\title{
Journal of Stroke (JoS) Receives High Impact Factor
}

\author{
Jong S. Kim \\ Editor-in-Chief, Journal of Stroke
}

I am pleased to inform you that the first impact factor for the "JOURNAL OF STROKE (JoS)" has recently been reported to be high, 4.795 (Thomson Reuters Journal Citation Reports ${ }^{\circledR}, 2016$ ). Of the international journals dedicated to clinical stroke research, ours has the highest impact factor, lower only than that of Stroke. Although the impact factor is just one measure of the quality of a journal, this news clearly indicates that JoS has rapidly grown to become a widely cited, international journal. The JoS, now a 'Jaws' in the stroke literature, is an important player in the dissemination of stroke research.

For this, I am indebted to the; authors, who sent us excellent reviews and original articles; readers who have cited our works; editorial board members; and executive members of the Korean Stroke Society, who have generously supported us. Above all, I would like to express my sincere thanks to our editorial team, OY Bang, DW Kang, JS Lee and SY Hwang, for their hard work.
Although our initial leap was quite successful, we know well that JoS is still a young journal that needs to be nourished by increasing international exposure and excellent quality papers. We will try our best to at least maintain, and hopefully increase, the impact factor and to make JoS a truly high-quality, world-level journal. Thank you very much for your continuous support of JoS.
Correspondence: Jong S. Kim

Department of Neurology, Asan Medical Center, University of Ulsan, 88 Olympic-ro 43-gil, Songpa-gu, Seoul 05505, Korea E-mail: jongskim@amc.seoul.kr

The author has no financial conflicts of interest. 